\title{
ATRAVESSAR UMA QUESTÃO E COMPARTILHAR A ESCRITA*
}

\section{José Teixeira Neto**}

\begin{abstract}
Resumo: No texto, compartilho a preparação e o desenvolvimento da disciplina Tópicos específicos de Filosofia e seu Ensino no Núcleo do Mestrado Profissional em Filosofia-PROF-FILO da Universidade do Estado do Rio Grande do Norte-UERN. Não pretende ser um mero relato, pois não se trata apenas de por meio de um exercício de memória recuperar fatos. Compartilho as escolhas e as direções que a questão-chave do curso foi indicando, os seus atravessamentos e acontecimentos. Compartilho o que recebi dos alunos, de outros olhares e de outras rotas traçadas por aqueles que também atravessam as questões postas pela Filosofia e pelo Ensino de Filosofia. O curso de Tópicos específicos de filosofia e seu ensino foi pensado em dois momentos: colocar uma questão e ler e escrever como modos de atravessar a questão. Compartilho o trabalho formativo que tentei desenvolver $e$ que passa por prestar atenção e se dispor a escutar o que outros estão fazendo, pensando e escrevendo. Nesse sentido, busco incluí-los no processo formativo que tento desenvolver. Por outro lado, o curso não aconteceria sem a partilha singular dos próprios alunos que atravessaram a questãochave com indicações de leituras e com a própria escrita.
\end{abstract}

Palavras-chave: Formação Docente; Ensino de Filosofia; PROF-FILO.

Resumen: En el texto, comparto la preparación y el desarrollo de la disciplina Temas específicos de filosofia e seu ensino en el Núcleo del Mestrado Profissional em Filosofia-PROF-FILO de la Universidade do Estado do Rio Grande do Norte -UERN. No pretende ser una mera cuenta, ya que no se trata solo de recuperar hechos a través de un ejercicio de memoria. Comparto las opciones y direcciones que indicaba la pregunta clave del curso, sus cruces y eventos. Comparto lo que recibí de los estudiantes, lo que recibí desde otras perspectivas y desde otras rutas trazadas por aquellos que también pasan por las preguntas planteadas por la Filosofía y la Enseñanza de la Filosofía. El curso sobre temas específicos de filosofía y su enseñanza se diseñó en dos etapas: hacer una pregunta y leer y escribir como formas de cruzar la pregunta. Comparto el trabajo de capacitación que intenté hacer y que implica prestar atención y estar dispuesto a escuchar lo que otros están haciendo, pensando y escribiendo. En este sentido, trato de incluirlos en el proceso formativo que trato de desarrollar. Por otro lado, el curso no se llevaría a cabo sin el intercambio singular de los propios estudiantes que pasaron por la pregunta clave con indicaciones de lecturas y con la escritura misma.

Palabras claves: Formación del Profesorado; Enseñanza de la Filosofía; PROF-FILO.

$O$ que significa ensinar Filosofia $e$ desde qual perspectiva filosófica se pode

\footnotetext{
* Texto originalmente apresentado no VI Encontro Nacional do GT Filosofar e Ensinar a Filosofar da Associação Nacional de Pós-Graduação em FilosofiaANPOF na mesa Formação docente no ensino de filosofia: olhares múltiplos e rotas compartilhadas juntamente com o Prof. Dr. Christian Lindberg L. do Nascimento (UFS e Prof-Filo/UFPE) e o Prof. Dr. Flávio de Carvalho (Prof-Filo/UFCG). O evento foi realizado no período de 15 a 17 de outubro de 2019 na UFMA, em São Luís-MA.
}

fazê-lo? A urgência e pertinência da questão irrompeu em 2017 no reencontro com exalunos da licenciatura, agora como professores da rede básica e alunos no componente curricular Filosofia do Ensino de Filosofia no Mestrado Profissional em Filosofia-PROF-

\footnotetext{
*** Professor Adjunto IV, com dedicação exclusiva, da Universidade do Estado do Rio Grande do NorteUERN, Curso de Filosofia do Campus Caicó-CaC e Professor do Mestrado Profissional em Filosofia PROF-FILO/UERN. E-mail: joseteixeira@uern.br
}

NETO, José Teixeira. Atravessar uma questão e compartilhar a escrita. Revista Sul-Americana de Filosofia e Educação. Número 34: nov. 2020 - abril 2021, p. 44-58. DOI: https://doi.org/10.26512/resafe.v2i34.35131 
FILO. Naqueles reencontros, questionávamos sobre o que fazíamos na Escola em nome da Filosofia e como o que fazíamos estava ou não vinculado com uma determinada relação mais singular ou subjetiva com a própria Filosofia. (KOHAN, 2002, p. 22; CERLETTI, 2009, p. 13; TOMAZZETI, 2013, p. 39).

A área de pesquisa "Ensino de Filosofia", por um lado, especifica um problema que não interessa a área "Filosofia" $e$, por outro, escapa da tendência de apenas indicar o que os filósofos pensaram/disseram sobre a educação. A área "Ensino de Filosofia" questiona o ensinar e o aprender Filosofia e direciona o pesquisador a manter como questão central a pergunta "O que é filosofia?", pois a tonalidade com a qual o professor-filósofo trata ${ }^{3}$ essa questão, orienta o que e o como ensinar. A questão "o que é Filosofia?" ou a relação inicialmente singular $e$ subjetiva que vou mantendo com a Filosofia é a que mais me orienta ao pensar as estratégias didáticas, as metodologias, os conteúdos quando me proponho a ensinar Filosofia. A área "Ensino de Filosofia", no meu caso, me alertou e me deixa atento à questão: que relação mantenho com a Filosofia $e$ como essa relação implica na minha atividade de ensiná-la e de propiciá-la aos alunos da licenciatura e do Mestrado Profissional?

\footnotetext{
3 "Tratar uma questão não é o mesmo que responder a ela. Responder-lhe pode ser a pior coisa a fazer. Creio que isso ocorra em filosofia. Responder a uma pergunta antes de entender o que é e de onde vem é como aplicar uma cura a uma doença sem ter identificado que doença é. Pode fazer o quadro piorar, e certamente dificultar a identificação e o entendimento. Para entender o que teses ou o que teorias filosóficas são, temos de entender a natureza e as fontes dos problemas para os quais elas são soluções. E para entender esses problemas precisamos identificar $e$ entender suas fontes". (STROUD, 2015, p. 14).
}

Já em 2019, ainda no âmbito Mestrado Profissional, ao preparar o componente Tópicos específicos de filosofia e seu ensino $e$ influenciado pela leitura de $O$ mestre ignorante de Jacques Rancière (2016), aquela questão central me levou para além da pergunta sobre o ensino, a pensar sobre a aprendizagem em Filosofia. A "consequência capital" para o "Mestre" da "situação experimental criada por Jacotot", uma "experiência pedagógica [que] abria [...], uma ruptura com a lógica de todas as pedagogias" (RANCIÈRE, 2016, p. 32), era que os alunos:

[...] haviam aprendido sem mestre explicador, mas não sem mestre. Antes, não sabiam e, agora, sim. Logo, Jacotot havia lhes ensinado algo. No entanto, ele nada lhes havia comunicado de sua ciência. Não era, portanto, a ciência do Mestre que os alunos aprendiam. (RANCIÈRE, 2016, p. 32).

$\mathrm{O}$ que os alunos aprendiam quando o mestre ensinava, mas não comunicava a sua ciência? Portanto, a orientação do curso de Tópicos específicos de filosofia e seu ensino se insinuava na paradoxal relação entre o ensinar e o aprender Filosofia. Quanto a esse aspecto, nada de novo. Lembro que para Gallo (2003, p. 209-210) a expressão "ensino-aprendizagem" pode sugerir que o "ensinado é aprendido". Além disso, segundo Gallo, essa expressão caiu "num modismo maneiro" e já não significa "grande coisa". Apesar desses questionamentos e desconfiando, como sugere o próprio Gallo, "[...] da certeza fácil de que aquilo que é ensinado é aprendido", mantenho a expressão "ensinoaprendizagem" para insistir que a prática educativa-pedagógica do professor-filósofo (seus estudos e suas preocupações em com- 
partilhar o que estuda) não está dissociada do cuidado com aqueles a quem essas pesquisas são propiciadas. Parece-me possível manter a expressão "ensino-aprendizagem" desde que a relação mestre-aluno não se baseie necessária e exclusivamente no processo de ensino-aprendizagem desigual no qual o mestre ensina enquanto sabe e o aluno, enquanto não sabe, aprende. Não se trataria do ensinar e do aprender em que se transmitiriam conteúdos, mas em que se compartilhariam gestos e em que o mestre propiciaria algo ao aluno e o faria desejar saborear a Filosofia.

Kohan (2013, p. 83), por outro lado, problematizou essa relação da seguinte forma:

À primeira vista, o professor ensina e o aluno aprende. O professor dá e o aluno recebe. Mas nessa simplicidade esconde-se um mundo complexo: nem sempre aprendemos o que alguém nos ensina. Nem sempre ensinamos o que alguém aprende. Mais ainda, nem tudo o que se aprende é ensinado. Nem tudo o que se ensina é aprendido. Ensinar e aprender não conformam um processo contínuo, unidirecional, antecipável.

Por sua vez, Antônio Joaquim Severino (2002, p. 184) afirmou que "No caso dos homens, a aprendizagem é muito mais complexa e se acompanha de um processo muito mais sofisticado que se chama 'formação', ou seja, quando falamos de educação na escola, estamos falando não só de ensino/aprendizagem, mas também, e fundamentalmente de formação". Mais à frente Severino (2002, p. 187) sugere que a educação enquanto formação não pode acontecer "[...] sem a participação, sem o exercício e o cultivo da filosofia, [...]". O primeiro direcionamento para o curso, portanto, tratava-se de abordar o ensino-aprendizagem na perspectiva da Filosofia.

Mas, o que eu pretendia problematizar com os alunos de Tópicos específicos de filosofia e seu ensino não era somente a expressão "ensino-aprendizagem", mas sugerir que talvez na área "Ensino de Filosofia" tenhamos sidos conduzidos a pensar demasiadamente um polo da expressão em detrimento do outro; temia que houvéssemos esquecido do aspecto da aprendizagem. Assim, antes mesmo de iniciar o curso, encaminhei para os e-mails dos alunos da turma do PROF-FILO uma lista com títulos de artigos que havia selecionado a partir de uma pesquisa aleatória sobre os temas "ensinar" e "aprender" na interface com a Filosofia. Esse trabalho, apesar de oferecer alguns resultados, não me pareceu promissor, pois essa forma de checagem se mostrou aberta $e$ omnidirecional. Então, decidi verificar a partir dos pesquisadores dos núcleos de sustentação e apoio do GT Filosofar e Ensinar a Filosofar. Copiei a partir do lattes todos os títulos de artigos publicados por esse grupo de pesquisadores e nos quais aparecessem os verbos "ensinar" e "aprender", os substantivos derivados deles na relação com a Filosofia e com a Educação etc. ${ }^{4}$.

A ideia inicial era mostrar para os alunos como a área de "Ensino de Filosofia" vem se constituindo no Brasil a partir desse grupo de pesquisadores; quais os tópicos

\footnotetext{
${ }^{4}$ Para completar esse trabalho seria interessante ainda destacar os livros, capítulos de livros, trabalhos publicados em anais de eventos, projetos de pesquisa $e$ extensão.
} 
que recebem mais atenção nas pesquisas realizadas nos últimos anos etc. Antes do primeiro encontro do componente curricular Tópicos específicos de filosofia e o seu ensino indiquei, primeiramente, para os alunos, via e-mail, que havia feito a pesquisa como relatado no parágrafo anterior e havia encontrado uns 190 artigos escritos nos dez últimos anos na área temática "Ensino de Filosofia" dos quais uns 150 foram escritos pelo grupo do GT Filosofar e Ensinar a Filosofar. A partir de uma tabela pude indicar o seguinte sobre a aparição dos termos "ensino"; "ensino de filosofia"; "ensinar" e "ensinar filosofia" e sobre os termos "aprender"; "aprender filosofia" e "aprendizagem" $e$ "aprendizagem de filosofia"

\begin{tabular}{|l|l|}
\hline Termo & $\begin{array}{l}\text { Quantidade que } \\
\text { aparecem nos títulos }\end{array}$ \\
\hline Ensino & 150 vezes \\
\hline Ensino de Filosofia & 81 vezes \\
\hline Ensinar & 6 vezes \\
\hline Ensinar filosofia & 3 vezes \\
\hline Ensino filosófico & 0 vezes \\
\hline Aprender & 3 vezes \\
\hline Aprender filosofia & 1 vez \\
\hline Aprendizagem & 08 vezes \\
\hline $\begin{array}{l}\text { Aprendizagem de filoso- } \\
\text { fia }\end{array}$ & 0 \\
\hline Aprendizagem filosófica & 4 vezes \\
\hline Ensino e aprendizagem & 1 vez \\
\hline Ensinar e aprender & 1 vez \\
\hline
\end{tabular}

Esses números talvez não digam muita coisa, pois a análise dos artigos poderia mostrar que quando se pensa e se escreve sobre o "ensino" também se pensa e se escreve sobre a "aprendizagem", necessariamente e vice-versa. Além disso, o título do artigo nem sempre apresenta todo o conteúdo a ser nele discutido. Porém, naquele momento esses números pareciam sugerir duas coisas: a) as pesquisas poderiam estar direcionadas apenas para o ensino e, portanto, para o professor e, por isso, quase sempre se pesquisaria sobre estratégias didáticas e metodológicas a serem adotadas pelo pro-

\footnotetext{
5 Indico os títulos nos quais aparecem o termo "aprender" e "aprendizagem" e suas interfaces com o ensino da Filosofia ou com a Educação de modo geral: Sobre ensino, aprendizagem e resistência na aula de filosofia no Ensino Médio (TOMAZETTI, 2009); Desencontros entre ensinar e aprender filosofia (CEPPAS, 2011); Produção discursiva sobre ensino e aprendizagem filosófica (TOMAZETTI, 2012); Filosofia da diferença: apontamentos em torno da aprendizagem do pensamento em filosofia (GRISOTTO, 2012); Formação do professor de Filosofia: entre o ensino e a aprendizagem (TOMAZETTI; BENETTI, 2012); Experiência e aprendizagem no ensino de filosofia (PINTO; SANTOS, 2013); Anticoncepção de ensino de filosofia para a educação básica global: a aprendizagem filosófica dialógica transdisciplinar (GALEFFI, 2013); Entre a filosofia e a vida: o que é possivel pensar e aprender com o projeto existencial de Michel Onfray? (BADIA; OLIVEIRA, 2016); O aprender em múltiplas dimensóes (GALLO, 2017); Para que serve ensinar filosofia na educação disciplinar? Projeto/invenção da aprendizagem filosófica no educar transdisciplinar (GALEFFI, 2017); Encontros com signos: possibilidades para pensar a aprendizagem no contexto da educação (NEUSCHARANK; OLIVEIRA, 2017).
} 
fessor para as aulas de Filosofia; b) segundo, ao esquecer o aspecto da "aprendizagem", as pesquisas também poderiam esquecer dos alunos e de como eles aprendem; para verificar essas hipóteses seria necessário analisar todos os artigos, coisa que não fiz. Na maioria dos casos me limitei a uma análise dos resumos e das palavras-chave. Porém, esses números me pareceram suficientes para direcionar, naquele momento, o curso de Tópicos específicos de filosofia e seu ensino para uma discussão sobre a aprendizagem em Filosofia já que paralelamente o Prof. Marcos de Camargo von Zuben havia solicitado para o componente Filosofia do ensino de filosofia, disciplina que se desenvolvia no mesmo período, que os alunos escrevessem um artigo tratando a questão: o que é Filosofia para o filósofo que vocês estão estudando na parte teórico-crítica da dissertação do PROF-FILO e como elaborar uma proposta de ensino de Filosofia a partir dessa perspectiva filosófica? Desse modo, as rotas dos dois componentes curriculares do Núcleo do PROF-FILO da UERN se cruzariam, uma mais voltada para elaborar uma proposta de ensino e outra mais voltada para uma discussão sobre a aprendizagem e para o professor quando o seu papel não se resume a explicar e passar conteúdos.

Ao iniciar o curso, porém, era necessário dimensionar a questão da aprendizagem, pois pensar a aprendizagem não poderia significar afirmar a "ausência" ou a "negação" do professor e da Escola. Para tanto, em primeiro lugar, mantivemos no horizonte sempre a lição de $O$ mestre ignorante, ou seja, os alunos "haviam aprendido sem mestre explicador, mas não sem mestre" $e$, portanto, que os alunos aprenderam, mas não aprenderam a ciência do mestre (RANCIÈRE, 2016, p. 31). Em uma sociedade pedagogizada e que sobrevive do mito da explicação (RANCIÈRE, 2016), manter essa lição, implicava em forçar os alunos do PROFFILO, a pensarem o papel deles enquanto professores de Filosofia quando a lógica da explicação é anulada.

Em segundo lugar, era necessário também afirmar que apostar na aprendizagem não significava negar a Escola e, por isso mesmo, não significava valorizar a autoaprendizagem. Nesse sentido, compartilho aqui a ideia de "sociedade da aprendizagem" que rabisquei no meu caderno durante uma conferência da Professora Elizete Tomazetti (2019) em abril de 2019 em Caicó$\mathrm{RN}$ e que agora cito de modo mais apropriado a partir do texto publicado na revista Trilhas filosóficas.

\begin{abstract}
Desenvolvo minhas reflexões em dois momentos. No primeiro apresento alguns argumentos de defesa da escola no mundo contemporâneo, o qual tem sido embalado pelo canto sedutor de uma sociedade da aprendizagem, cujo discurso diz que todos podem aprender em diferentes tempos e espaços, pela mediação das tecnologias digitais. (TOMAZETTI, 2019, p. 17. Grifo nosso).
\end{abstract}

Para aprofundar essa questão da "sociedade da aprendizagem" apontada por Tomazetti (2019) fizemos a leitura do capítulo intitulado "Contra a Aprendizagem - Recuperando uma linguagem para a educação numa era da aprendizagem" do livro Para além da aprendizagem - Educação democrática para um futuro humano. Nesse capítulo, Biesta (2013, p. 30. Grifo do autor) aponta 
que a "Linguagem da educação tem sido em grande parte substituída pela linguagem da aprendizagem" e que

Há [...] duas objeções contra a nova linguagem da aprendizagem ou, para ser mais preciso, contra uma linha de pensamento que se tornou possível pela nova linguagem da aprendizagem. Um problema é que a nova linguagem da aprendizagem facilita uma compreensão econômica do processo da educação, na qual o aprendente supostamente sabe $\mathrm{o}$ que ele ou ela deseja e na qual o provedor se apresenta simplesmente para satisfazer as necessidades do aprendente (ou, em termos mais diretos: para satisfazer o cliente). Tenho mostrado como essa descrição interpreta mal a dinâmica das relações educacionais. O outro problema com a lógica da nova linguagem da aprendizagem é que ela torna muito difícil propor questões sobre o conteúdo e o objetivo da educação que não sejam aquelas formuladas em termos do que 'o cliente' ou 'o mercado' deseja. Isso, tenho afirmado, representa uma ameaça ao profissionalismo educacional e acaba solapando a deliberação democrática sobre os objetivos da educação.

Portanto, ao chamar a atenção dos alunos do PROF-FILO para o tema da "aprendizagem" ao mesmo tempo em que nos afastávamos desses aspectos denunciados por Tomazetti (2019) e Biesta (2013), mantivemos a Escola e o professor como intrínsecos ao ato pedagógico e à experiência do ensinar-aprender. Porém, não questionamos durante o curso o lugar da Escola, mas apenas o papel do professor de Filoso- fia, como dissemos, quando a lógica da explicação é destituída.

Relembremos o texto-chave de $O$ mestre ignorante (RANCIÈRE, 2016, p. 32): os alunos aprenderam sem mestre explicador, mas não sem mestre; Jacotot lhes havia ensinado algo, mas não lhes havia comunicado a sua ciência; os alunos não aprenderam a ciência do mestre. Os alunos não aprenderam somente a língua francesa sem a explicação de Jacotot, mas esse mestre lhes havia ensinado algo que não era o seu saber nem o seu conhecimento. Portanto, a "experiência pedagógica" de Jacotot, permite-nos supor que para a além da explicação, o professor pode outra coisa na Escola. $\mathrm{O}$ que pode o professor ensinar quando não está em jogo a comunicação e explicação daquilo que supostamente sabe? $\mathrm{O}$ que os alunos aprendem com o mestre quando não aprendem a sua ciência? Compartilho novamente aqui um outro trecho da conferência de Tomazetti (2019, p. 23):

\footnotetext{
Quando nos perguntamos sobre a tarefa do professor na escola e na sala de aula, quais são as primeiras respostas que são dadas? É um especialista em uma área de conhecimento, em uma disciplina, cuja tarefa é ensinar a quem não sabe. Sua tarefa é, pois, o ensino. Ou em outras palavras, o/a professor/a é aquele/a que tem domínio conceitual $e$ tem habilidades nos métodos para ensiná-la. No entanto, há algo mais a considerar na tarefa de ser docente: amor e cuidado.
}

Essas "primeiras respostas" (TOMAZETTI, 2019) ou, nas palavras de Kohan, a ideia de que "à primeira vista, o professor 
ensina e o aluno aprende. O professor dá e o aluno recebe" (KOHAN, 2013, p. 83) são também as primeiras respostas dos alunos do PROF-FILO, professores de Filosofia e às vezes de outros componentes na educação básica há pelo menos dez anos. Porém, o que salvei no rabisco daquela conferência foi a ideia de que existe algo inensinável na $\mathrm{Fi}$ losofia, mas que o aluno só pode aprender com o professor de Filosofia. Ao citar Masschelein e Simons e também Cerletti, Tomazetti (2019, p. 24) assim se expressou:

O professor (de filosofia) não ensina o 'amor pelo assunto' (2015, p. 81), pois não se ensina ninguém a amar a sabedoria, como escreve Cerletti (2009, p. 37-38). O amor, assim como o desejo diz 'do irredutível de cada um, por que diz respeito àquilo que cada um completará à sua maneira'. Entretanto, a presença do/a professor/a permanece importante. Cabe a ele/a planejar sua aula, buscar materiais didáticos e organizar a turma de modo que fique atenta ao que ali acontece.

O inensinável na Filosofia, mas que o aluno só aprende com o professor é, por isso, o amor, essa relação de philia com a sophia. Nesse sentido, em uma aula de Filosofia ensinamos o inensinável, aquilo que é próprio da Filosofia, quando ensinar não significa nem se restringe à comunicação nem à explicação do nosso saber. Talvez aí, na oportunidade do tempo do aluno, possa começar a acontecer uma relação que constitui e sustenta qualquer outra relação singular e subjetiva que o aluno vier a estabelecer com a Filosofia.
Essa rota compartilhada com $O$ mestre ignorante de Rancière (2017) e com Elisete Tomazetti (2019), levou-me a outra rota que pude compartilhar com os alunos do PROF-FILO, uma rota aberta por Flávio Carvalho (2019, p. 40) na conferência "A docência como questão filosófica: entre o esquecimento de si e a parresia", também proferida em Caicó-RN e agora publicada também na revista Trilhas filosóficas.

Sócrates escolheu o caminho da re-
volução nuclear, da autotransforma-
ção dos indivíduos, da autossupera-
ção de si, de modo que cada indiví-
duo seja capaz de construir sua exis-
tência como uma obra de arte, de
modo criativo e singular: 'Sócrates
cuida dos homens, mas não na for-
ma política: ele quer cuidar deles pa-
ra que eles aprendam a cuidar de si
mesmos'. (FOUCAULT, 2014 , p.
96). Seu testamento: cuidai de vós
mesmos!

A partir desses caminhos compartilhados que orientaram a questão-chave, passei para a segunda parte do curso: ler e escrever como modo de atravessar a questão. Por isso, decidimos, professor e alunos do PROF-FILO, ler a Apologia de Sócrates para meditarmos sobre dois aspectos que considerávamos importantes: em primeiro lugar a afirmação paradoxal de Sócrates de que nunca havia sido "mestre de ninguém", mas que alguns aprenderam com a sua atividade pública: "Quem afirmar que de mim aprendeu ou ouviu em particular alguma coisa que não todos os demais, estai certos de que não diz a verdade". (Apologia de Sócrates). Em segundo lugar, reler a partir da própria Apologia as rotas sugeridas por Flávio de 
Carvalho (2019) a partir da sua leitura de Foucault, ou seja, o tema do "cuidado de si" e dos outros. Para aprofundar essa temática, após a leitura da Apologia, o próximo passo foi ler o Capítulo II - Foucault e o cuidado de Sócrates e Capítulo IV - O Sócrates de Rancière do texto Sócrates \& a Educação $O$ enigma da filosofia de Walter Kohan (2011).

Portanto, tínhamos uma questão para o curso de Tópicos específicos de filosofia $e$ seu ensino e algumas rotas compartilhadas. Como se tratava de um curso com essas inspirações e indicações, sugeri para os encontros seguintes que cada aluno do componente curricular se propusesse a atravessar a questão indicando como rota leituras da parte teórico-crítica da dissertação em início de preparação para o PROF-FILO e que escrevessem um texto a partir da questão propos$\mathrm{ta}^{6}$.

\footnotetext{
${ }^{6}$ Indico a seguir algumas propostas de leitura na sequência em que os textos foram lidos durante o curso. a) Para o encontro dos dias 17 e 18 de maio de 2019 os alunos propuseram ler de Deleuze (1988) o texto $P$ de professor e de Silvio Gallo (2017) o texto $O$ Aprender em Múltiplas Dimensóes, de Ortega y Gasset (2000) o texto Sobre o estudar e o estudante e de Oliveria e Castro Filho (2016) o artigo Ortega y Gasset: uma possível contribuição para o ensino na atualidade, de Walter Kohan (2005) o texto Infância de um ensinar e aprender (J. Rancière) e Silva (2011) $A$ dialética socrática e a relação ensino-aprendizagem. b) Para os encontros dos dias 31 de maio e 01 de junho de 2019 foram propostos os seguintes textos: de Walter Kohan (2009) o texto O enigma paradoxo de aprender-ensinar filosofia; de Gimbo (2017) o artigo Emancipação intelectual e democracia: para uma filosofia crítica da educação a partir de Jacques Rancière e Paulo Freire; de Kahlmeyer-Mertens (2008; 2005) os artigos Cuidado, educação e singularidade: ideias para uma filosofia da educação em bases heideggerianas e Heidegger educador: acerca do aprender e do ensinar. c) Para os encontros dos dias 07 e 08 de junho de 2019 os alunos propuseram ler: de Walter Kohan (2013) o texto Antinomias para
}

No último encontro tivemos dois momentos conclusivos. O primeiro, uma oficina sobre a escrita cujo texto base foi o Vazio: condição da experiência-formação da Profa. Maria Reilta Dantas Cirino (2015) e três poemas de Manoel de Barros: O menino que carregava água na peneira; $O$ apanhador de desperdícios e O livro sobre nada. $\mathrm{O}$ segundo momento conclusivo foi um minicurso sobre Jacque Rancière e Foucault ministrado pelo Professor Flávio Carvalho cujo título "Filosofando entre Rancière e Foucault sobre a ordem do discurso da emancipação". A ideia central era traçar um exercício filosófico para pensar o discurso da emancipação e sua vinculação com as relações de poder na sociedade.

Por fim, é preciso compartilhar o acontecimento da escrita nos exercícios elaborados pelos alunos e registrar, pelo menos de alguns, o modo como atravessaram a questão-chave do curso. Aldo Batista de Azevedo Júnior, que escreveu um texto Sobre a prática filosófica: Gilles Deleuze professor, destaca sobre a possibilidade de "controlar o momento do ensino" e sobre a impossibilidade de "controlar a aprendizagem":

Para Deleuze há uma possibilidade
de se controlar o momento do ensi-
no, até mesmo preparado de manei-
ra a prever todos os passos a serem
seguidos, como num ensaio, mas há

pensar o ensino da filosofia e de Silvio Gallo (2013) o texto $O$ ensino da filosofia e o pensamento conceitual; de Sofiste (2007) o texto Sócrates e o ensino da filosofia. Investigação dialógica: uma pedagogia para docência de filosofia do qual foram indicadas as Unidade I (Fundamentação) e Unidade III (Sócrates: uma docência para ensino de filosofia) e, por fim, Antônio Joaquim Severino (s/d) o artigo $A$ filosofia na formação do jovem e a ressignificação de sua experiência existencial. 
uma impossibilidade de se controlar a aprendizagem, o momento da aprendizagem, como normalmente a compreendem as teorias pedagógicas modernas que formulam um verdadeiro arsenal de métodos de ensino-aprendizagem, cada um proclamando sua eficácia e produtividade. O professor, em sala de aula, pode emitir signos, mas esses signos só podem ser interpretados pelo aluno, da sua maneira e do seu jeito, totalmente fora do controle do professor. A aprendizagem terá seu momento apropriado, mas não se sabe quando será ou mesmo se isso se dará. (AZEVEDO JÚNIOR, 2019).

Em segundo lugar, trago um comentário do mesmo aluno a uma frase de Deleuze sobre a aula citada por Dosse e que o aluno grifou em seu texto: "Uma aula é emoção. Se não há emoção, não há inteligência, nenhum interesse, não há nada". (DELEUZE apud DOSSE, 2010, p. 291). Esse aspecto da "emoção", como destacará o aluno em seu comentário a seguir é central e pode ser interpretado a partir do conceito deleuziano "afecção" (affectio):

É necessário lembrar que todo o processo do pensar começa por uma afecção (affectio) que produz as ideias-afecções que por sua vez causam afetos alegres ou tristes (variações) $e$, assim, segue todo o movimento das faculdades na elaboração do pensamento. Dessa forma, somente os signos emitidos por algo ou alguém podem causar essa perturbação, nos encontros, que não podem ser controlados. A pergunta que se faz, então, é: como ensinar Filosofia em sala de aula, já que não se pode controlar o processo de aprendizagem, pois não se sabe como ele acontece porque para Deleuze "[...] 'aprender' passa sempre pelo inconsciente, dá-se sempre no inconsciente, estabelecendo, entre a natureza e o espírito, o liame de uma cumplicidade profunda". (DELEUZE, 2018, p. 222 apud AZEVEDO JÚNIOR, 2019).

Portanto, Azevedo Júnior (2019) sugere que como é impossível controlar a aprendizagem, restaria ao professor emitir signos em sala de aula na expectativa de que esses signos afetem ou não seus alunos $e$, assim, produzam pensamento.

Por sua vez, para Joildo Dutra de Medeiros, que escreveu sobre "Exercícios emancipatórios" para uma aprendizagem da filosofia no ensino médio a partir de $\mathrm{O}$ mestre ignorante de Jacques Rancière, é necessário retomar de $O$ mestre ignorante, no contexto do ensino-aprendizagem de Filosofia no Ensino Médio, a "igualdade de inteligências" e a "emancipação intelectual" e crítica às "pedagogias baseadas na lógica da explicação":

Para nós isso significa que a Filosofia não pode ser aprendida numa lógica da explicação, ela precisa de uma outra lógica. Expressa nos 'exercícios emancipatórios', essa 'outra lógica' da aprendizagem da Filosofia na escola, portanto, deve se sustentar na 'emancipação intelectual', segundo O Mestre Ignorante, e numa relação com a Filosofia na qual se privilegie não a transmissão ou o 'passar' e o 'reter' saberes e conteúdos da tradição, inócuos para a vida do aluno, mas na experiência do pensar que leve professores e alunos a uma transformação da relação com a própria Filosofia, com a escola $e$ com a vida. (MEDEIROS, 2019). 
Seguindo a rota de Ortega y Gasset, Joabe Tavares Pereira escreveu sobre Concepção de Filosofia e seu Ensino: A Filosofia como Remédio à Massificação Educacional. Nesse trabalho relaciona, a partir do filósofo espanhol, a "aprendizagem" e a "necessidade intelectual" dessa aprendizagem para o estudante. Portanto, conforme Ortega y Gasset, seria necessário "despertar no estudante a necessidade de uma ciência" e não simplesmente ensinar o que a ciência acumulou durante a sua história:

[...] em Ortega y Gasset (2000), a aprendizagem será tanto mais significativa quanto mais necessidade o estudante tiver dela, uma necessidade intelectual sentida por ele. Vale salientar que, 'ensinar é despertar no estudante a necessidade de uma ciência', como nos ensina Ortega y Gasset (1999), e não simplesmente ensinar conhecimentos científicos, acumulados no percurso da história, uma vez que isto não seria possível, pois os estudantes não têm naturalmente essa necessidade. Insistir com conteúdos históricos desprovidos de sentido para o estudante é tornar o ensino de filosofia mais um lugarcomum, mero penduricalho, do qual a escola básica já está abarrotada. Se o estudante não encontrar necessidade para aquilo que lhe é imposto, seria como se ele fosse '[...] convidado para uma ficção, para uma falsidade' (ORTEGA YGASSET, 2000, p. 91). Destarte, primeiro o estudante deve sentir necessidade, como se náufrago fosse, em seguida, de forma autêntica averiguar aquilo que busca assimilar. (PEREIRA, 2019).
Por fim, para pensar a relação entre ensinar e aprender a partir de Sócrates, compartilho a escrita da aluna Rosana Lopes dos Santos. A partir da leitura que faz de um texto de Walter Kohan Filosofia: o paradoxo de aprender e ensinar (2009) a aluna sugere que

[...] para Kohan (2009) Sócrates não consegue mensurar o que os seus alunos aprendem, mas provoca aprendizagens que ele não ensina. Não sabemos exatamente como se aprende $e$ a aprendizagem nos parece vir independente de alguém ter ensinado ou não; alguém pode aprender sem que outro o ensine. Não somente se aprende se o outro ensinou, uma pessoa pode aprender sem que esse movimento aconteça. Para Sócrates, segundo Kohan (2009), é possivel compartilhar o caminho com quem aprende. $\mathrm{O}$ professor de Filosofia tem esse papel de contribuir para a aprendizagem do educando. (SANTOS, 2019).

O papel do professor de Filosofia ou uma sua contribuição estaria ligado ao "compartilhar o caminho". "Compartilhar caminho" é ir juntos, lado a lado; cada um no seu passo, mas também um se aproximando do passo do outro; decidir juntos as veredas $e$ as trilhas a serem tomadas etc. Não é cada um por si. A partir daí se poderia dizer que "A lógica da relação pedagógica" não obedece a lógica da "simples transmissão de conhecimentos" (SANTOS, 2019) e que, por isso mesmo, acrescenta a aluna

[...] o pensamento é algo fundamental nesse aspecto, enquanto é ele que faz tudo funcionar. Nesse espa- 
ço há uma troca de experiências que faz o educando aprender, não somente ouvindo, como também participando ativamente da sua aprendizagem. Em uma relação entre quem ensina e quem aprende, voltada ao pensar, existe uma troca, sendo uma via de mão dupla. Pensamos com isso que $o$ ato de ensinar e aprender passa pelo pensar do outro com sensibilidade para que aquele que aprende tenha a liberdade de pensar de outra maneira. (SANTOS, 2019).

Colocar uma questão. Ler e escrever como modos de atravessar a questão. Prestar atenção e escutar como modos de problematizar e dimensionar a questão. Ponto de partida: teria a área "Ensino de Filosofia" desconsiderado o tema da aprendizagem $e$ considerado excessivamente o tema do ensino? A partir do lattes, a análise dos títulos e dos resumos de artigos publicados pelo grupo de sustentação e pelo grupo de apoio do GT Filosofar e Ensinar a Filosofar ligado à ANPOF sugeriu que nos últimos dez anos o tema da aprendizagem foi pouco considerado pelos integrantes desse GT. Nesse sentido, se justificaria que professor e alunos do componente curricular Tópicos específicos de filosofia e seu ensino no PROFFILO/UERN investigassem o tema da aprendizagem em Filosofia. Posta a questão nesses termos, o próximo passo foi o de dimensionar a questão. As rotas compartilhadas com $O$ mestre ignorante de Rancière (2017) impôs que a questão se orientasse pela pergunta: Qual o papel do professor quando a "ló- gica da explicação" é anulada? Com Tomazetti (2019) e com Rancière (2017), por sua vez, sugeri que isso não significaria sacrificar o professor nem a escola, mais que ambos são intrínsecos ao ato pedagógico de ensinar-apreender; que o professor de Filosofia pode outra coisa na escola além de transmitir conhecimentos e que o aluno só aprende com o professor o que é por si mesmo inensinável: o amor pelo sabedoria. Uma outra rota foi compartilhada por Flávio Carvalho (2019). A partir dela foram abertas as trilhas para a leitura de $A$ apologia de Sócrates e de capítulos de Sócrates \& a Educação de Walter Kohan (2011). O exercício de leitura, como parte do atravessamento da questãochave, também se estendeu para as propostas de leitura dos alunos. O segundo modo de atravessar a questão foi o da escrita. Escrever é traduzir em palavras o jogo que o pensamento joga sozinho. É partilha. Da partilha textual dos alunos, ouviu-se que a aprendizagem é incontrolável; que em sala de aula cabe ao professor emitir signos na expectativa que os alunos sejam afetados; que a lógica da aprendizagem não é a lógica da explicação ou da simples transmissão, pois a relação ensino-aprendizagem é, antes de tudo, compartilhar um caminho ou um gesto. 


\section{Referências}

AZEVEDO JÚNIOR, A. Sobre a prática filosófica: Gilles Deleuze professor. 2019. (Não publicado). Artigo apresentado no componente curricular Tópicos específicos de Filosofia e seu Ensino no Núcleo do Mestrado Profissional em Filosofia-PROF-FILO da Universidade do Estado do Rio Grande do Norte-UERN. Caicó-RN, 2019.

BADIA, D; OLIVEIRA, P. Entre a filosofia e a vida: o que é possível pensar e aprender com o projeto existencial de Michel Onfray?. Revista Sul-Americana de Filosofia da EducaçãoRESAFE. n. 27 (2016): nov. 2016/abr. 2017, p. 59-68. Disponível em: https://periodicos. unb.br/index.php/resafe/article/view/4878. Acesso em: 2020.

BARROS, M. O menino que carregava água na peneira; $\mathrm{O}$ apanhador de desperdícios e $\mathrm{O}$ livro sobre nada. In. LEITE,C. Os dez melhores poemas de Manoel de Barros. Revista Bula. Disponível em: https://www.revistabula.com/2680-os-10-melhores-poemas-de-manoel-debarros/. Acesso em: 07 mar. 2020.

BIESTA, G. Contra a Aprendizagem - Recuperando uma linguagem para a educação numa era da aprendizagem. In: BIESTA, G. Para além da aprendizagem - Educação democrática para um futuro humano. Belo Horizonte: Autêntica, 2013.

CARVALHO, F. A docência como questão filosófica: entre o esquecimento de si e a parresia. Trilhas Filosóficas. Caicó, ano 12, n. 1, 2019, p. 27-43. Dossiê Introdução à Filosofia e Filosofia do Ensino de Filosofia. Disponível em: http://natal.uern.br/periodicos/index.php/ RTF/article/view/23/19. Acesso em: 06 mar. 2020.

CEPPAS, F. Desencontros entre ensinar e aprender filosofia, Revista Sul-Americana de Filosofia da Educação-RESAFE. n. 15 (2010): nov. 2010/abr. 20112011.

CERLETTI, A. O ensino de filosofia como problema filosófico. Tradução de Ingrid Müller Xavier. Belo Horizonte: Autêntica editora, 2009. - (Coleção Ensino de Filosofia).

CIRINO, M. Vazio: condição da experiência-formação. In: VIII Seminário Internacional. As Redes e as Tecnologias: Movimentos Sociais e a Educação - (Junho/2015). ISBN 978-858427-027-9. CD ROM. Eixo 4: Estudos da infância e da juventude. Universidade do Estado do Rio de Janeiro-UERJ. 08 a 11 de junho de 2015. Disponível em: http:// www.seminarioredes.com.br/viiiredes/adm/diagramados/TR220.pdf. Acesso em 07 mar. 2020.

DELEUZE, G. P de professor. In. DELEUZE, G. O abecedário de Gilles Deleuze. Entrevista concedida a Clair Parnet, 1988. Transcrição integral do vídeo, para fins meramente didáticos. Disponível em: http://stoa.usp.br/prodsubjeduc/files/262/1015/Abecedario+G.+Deleuze.pdf. Acesso em: 08 abr. 2020.

GALEFFI, D. Para que serve ensinar filosofia na educação disciplinar? Projeto/invenção da aprendizagem filosófica no educar transdisciplinar. Ideação. Edição especial, 2017, p. 19-50. Disponível em: http://periodicos.uefs.br/index.php/revistaideacao/article/view/2985/2371. Acesso em: 08 mar. 2020. 
. Anticoncepção de ensino de filosofia para a educação básica global: a aprendizagem filosófica dialógica transdisciplinar. Global Education Magazine. Disponível em: http://www.globaleducationmagazine.com/anticoncepcao-de-ensino-de-filosofia-paraeducacao-basica-global-aprendizagem-filosofica-dialogica-transdisciplinar/. Acesso em: 08 mar. 2020.

GALLO, S. O aprender em múltiplas dimensões. Perspectivas de Educação Matemática. Revista do Programa de Pós-Graduação em Educação Matemática da Universidade Federal de Mato Grosso Do Sul (UFMS). Volume 10, número 22 - Seção Temática - 2017. http://www.edumat.ufms.br/

O ensino da filosofia e o pensamento conceitual. In. CARVALHO, Marcelo; CORNELLI, Gabriele. Filosofia e formação. Volume 1. Cuiabá-MT: Central do Texto, 2013, p. 205-215.

GIMBO, F. Emancipação intelectual e democracia: para uma filosofia crítica da educação a partir de Jacques Rancière e Paulo Freire. Griot: Revista de Filosofia v .16, n.2, dezembro/2017, p. 270-284.

GRISOTTO, A. Filosofia da diferença: apontamentos em torno da aprendizagem do pensamento em filosofia. ETD - Educ. Tem. Dig., Campinas, v.14, n.1, p.179-198, jan./jun. 2012, p. $179-198$.

KAHLMEYER-MERTENS, R. educação e singularidade: ideias para uma filosofia da educação em bases heideggerianas. Princípios. Natal, v 15, n. 24, jul./dez. 2008, p. 209-223.

Heidegger educador: acerca do aprender e do ensinar. APRENDER - Cad. de Filosofia $e$ Psic. da Educação. Vitória da Conquista Ano III n. 4 p. 161-171 2005

KOHAN, W. Antinomias para pensar o ensino da filosofia. In. CARVALHO, Marcelo; CORNELLI, Gabriele. Filosofia e formação. Volume 1. Cuiabá-MT: Central do Texto, 2013, p. 183-192.

. Sócrates \& a Educação: o enigma da filosofia. Tradução Ingrid Müller Xavier. Belo Horizonte: Autêntica Editora, 2011.

O enigma paradoxo de aprender-ensinar filosofia. In. KOHAN, Walter. Filosofia: O paradoxo de aprender e ensinar. Tradução de Ingrid Müller Xavier. Belo Horizonte: Autêntica, 2009 , p. $67-91$.

. Infância de um ensinar e aprender (J. Rancière). KOHAN, Walter. Entre educação e filosofia. Belo Horizonte: Autêntica, 2005, p. 181-205.

KOHAN, W. O. Perspectivas Atuais do Ensino de Filosofia no Brasil. In: FÁVERO, A. A.; RAUBER, J. J.; KOHAN, W. O. (Org.). Um olhar sobre o ensino de filosofia. Unijuí: Editora UNIJUÍ, 2002, p. 21-40. 
MEDEIROS, J. "Exercícios emancipatórios" para uma aprendizagem da filosofia no ensino médio a partir de $\mathrm{O}$ mestre ignorante de Jacques Rancière. 2019. (Não publicado). Artigo apresentado no componente curricular Tópicos específicos de Filosofia e seu Ensino no Núcleo do Mestrado Profissional em Filosofia-PROF-FILO da Universidade do Estado do Rio Grande do Norte-UERN. Caicó-RN, 2019.

NEUSCHARANK, A; OLIVEIRA, M. Encontros com signos: possibilidades para pensar a aprendizagem no contexto da educação. Educação, Santa Maria, v. 42, n. 3, p. 585-596, set./dez. 20172017.

OLIVEIRA, R; CASTRO FILHO, C. Ortega y Gasset: uma possível contribuição para o ensino na atualidade. Revista de Ciências Humanas. V 17, n. 29, p.66-87, Dez. 2016. Disponível em: http://revistas.fw.uri.br/index.php/revistadech/article/view/2207. Acesso em 14 jul. 2019.

ORTEGA y GASSET, J. Sobre o estudar e o estudante. In. Quatro textos excêntricos. Lisboa: Relógios D’água Editores, 2000, p.87-103.

PEREIRA, J. Concepção de Filosofia e seu Ensino: A Filosofia como remédio à massificação educacional. 2019. (Não publicado). Artigo apresentado no componente curricular Tópicos específicos de Filosofia e seu Ensino no Núcleo do Mestrado Profissional em Filosofia-PROFFILO da Universidade do Estado do Rio Grande do Norte-UERN. Caicó-RN, 2019.

PINTO, S; SANTOS, G. Experiência e aprendizagem no ensino de filosofia. Filogênese. Vol. 6, $n^{\circ} 2$, 2013, p. 133-147. Disponível em: https://www.marilia.unesp.br/Home/ RevistasEletronicas/FILOGENESE/silmaraegenivaldo.pdf. Acesso em: 08 mar. 2020.

SANTOS, R. Sobre a aprendizagem na filosofia. 2019. (Não publicado). Artigo apresentado no componente curricular Tópicos específicos de Filosofia e seu Ensino no Núcleo do Mestrado Profissional em Filosofia-PROF-FILO da Universidade do Estado do Rio Grande do NorteUERN. Caicó-RN, 2019.

SEVERINO, A. A filosofia na formação do jovem e a ressignificação de sua experiência existencial. (s/d). Disponível em: https://filosofiapibidufabc.files.wordpress.com/2011/09/ severino.pdf. Acesso em 28.08.2019. Acesso em: 08 abr. 2020.

SILVA, F. A dialética socrática e a relação ensino-aprendizagem. Ciências \& Cognição 2011; Vol 16 (1): 058-074, p. 58-74. Disponível em: http://www.cienciasecognicao.org/revista/ index.php/cec/article/download/381/476. Acesso em: 08 abr. 2020.

SOFISTE, J. Sócrates e o ensino da filosofia. Investigação dialógica: uma pedagogia para docência de filosofia. Petrópolis, RJ: Vozes, 2007.

STROUD, B. O que é a filosofia? SKÉPSIS, ISSN 1981-4194, ANO IX, No. 13, 2015, p. 1-17. Tradução: Israel Vilas Bôas; Revisão: Plínio Junqueira Smith. Disponível em: 
http://philosophicalskepticism.org/wp-content/uploads/2016/07/1-Barry-Stroud-O-que\%C3\%A9-a-filosofia.pdf Acesso em 07 de out. de 2019.

TOMAZETTI, E. Quando militância significa defender a escola e a docência. Trilhas filosóficas. Caicó, ano 12, n. 1, 2019, p. 15-16. Dossiê Introdução à Filosofia e Filosofia do Ensino de Filosofia. Disponível em: http://natal.uern.br/periodicos/index.php/RTF/article/ view/7/16. Acesso em 06 abr. 2020.

Filosofia como disciplina: entre a instituição, a vigilância e o pensar filosófico. In: SÁ JÚNIOR, Lucrécio A. de; BIELLA, Jaime. (Org.). Filosofia no ensino médio: desafios e perspectivas. Natal, RN: Edufrn, 2013, p. 37-49.

Produção discursiva sobre ensino e aprendizagem filosófica. Educ. rev. [online]. 2012, n.46, pp.83-98. Disponível em: http://www.scielo.br/pdf/er/n46/n46a07.pdf. Acesso em: 08 abr. 2020.

. Sobre ensino, aprendizagem e resistência na aula de filosofia no Ensino Médio. Revista Sul-Americana de Filosofia e Educação (RESAFE), n. 13, p. 41-53, 5 out. 2011. Disponível em: https://periodicos.unb.br/index.php/resafe/article/view/4380. Acesso em: 08 abr. 2020.

; BENETTI. Formação do professor de Filosofia: entre o ensino e a aprendizagem. Rev. Diálogo Educ., Curitiba, v. 12, n. 37, p. 1027-1043, set./dez. 2012. Disponível em: https://periodicos.pucpr.br/index.php/dialogoeducacional/article/download/4888/4846. Acesso em: 08 abr. 2020. 